\title{
A Pilot Investigation of the Short-Term Effects of an Interdisciplinary Intervention Program on Elderly Patients with Hip Fracture in Taiwan
}

\author{
Yea-Ing Lotus Shyu, PhD, ${ }^{* \dagger}$ Jersey Liang, PhD, ${ }^{\#}$ Chi-Chuan Wu, MD, ${ }^{\ddagger}$ Juin-Yih Su, MD, ${ }^{\mathcal{S}}$ \\ Huey-Shinn Cheng, MD," Shih-Wei Chou, MD, PhD, "and Ching-Tzu Yang, MSN ${ }^{\dagger}$
}

OBJECTIVES: To evaluate an interdisciplinary intervention program for older people with hip fracture in Taiwan. DESIGN: Randomized experimental design.

SETTING: A 3,800-bed medical center in northern Taiwan.

PARTICIPANTS: Elderly patients with hip fracture $(\mathrm{N}=137)$ were randomly assigned to an experimental $(\mathrm{n}=68)$ or control $(\mathrm{n}=69)$ group.

INTERVENTION: An interdisciplinary program of geriatric consultation, continuous rehabilitation, and discharge planning.

MEASUREMENTS: Demographic and outcome variables were measured. Outcome variables included service utilization, clinical outcomes, self-care abilities, health-related quality-of-life (HRQOL) outcomes, and depressive symptoms.

RESULTS: Subjects in the experimental group improved significantly more than those in the control group in the following outcomes: ratio of hip flexion 1 month after discharge $(P=.02)$, recovery of previous walking ability at 1 month $(P=.04)$ and 3 months $(P=.001)$ after discharge, and activities of daily living at 1 month $(P=.01)$ and 2 months $(P=.001)$ after discharge. Three months after discharge, the experimental group showed significant improvement in peak force of the fractured limb's quadriceps $(P=.04)$ and the following health outcomes: bodily pain $(P=.03)$, vitality $(P<.001)$, mental health $(P=.02)$, physical function $(P<.001)$, and role physical $(P=.006)$. They also had fewer depressive symptoms $(P=.008) 3$ months after discharge.

From the *Center for Gerontological Research, 'School of Nursing, and Departments of ${ }^{\ddagger}$ Orthopedics, ${ }^{\S}$ Trauma and Emergency Surgery, "Internal Medicine, and "Physical Therapy, Chang Gung University, Kweishan, Taoyuan, Taiwan; and "Health Management and Policy, School of Public Health, University of Michigan, Ann Arbor, Michigan.

Support was provided by the National Health Research Institute, Taiwan and Chang Gung Memorial Hospital, Taiwan.

Address correspondence to Yea-Ing Lotus Shyu, Center for Gerontological Research, Chang Gung University, 259 Wen-Hua 1st Road, Kwei-Shan, Tao-Yuan 333, Taiwan. E-mail: yeaing@mail.cgu.edu.tw

DOI: $10.1111 / \mathrm{j} .1532-5415.2005 .53253 . \mathrm{x}$
CONCLUSION: This intervention program may benefit older people with hip fractures in Taiwan by improving their clinical outcomes, self-care abilities, and HRQOL and by decreasing depressive symptoms within 3 months after discharge. J Am Geriatr Soc 53:811-818, 2005.

Key words: interdisciplinary intervention; hip fracture; older people; health-related quality of life; geriatric depression

$T$ he incidence of hip fracture worldwide in 1990 was 1.6 million. With the aging of the world population, this number is projected to become 6.26 million in $2050 .{ }^{1}$ The mortality rate for elderly patients within 1 year of hip fracture in the United States has been reported to range from $13 \%$ to $36 \% .^{2,3}$ Not only does the physical function of older people decline soon after hip fracture, but a large percentage (26-76\%) who survive the first or even the second year after a hip fracture fail to regain their prefracture level of physical function. ${ }^{4-6}$ Consequently, hip fracture has become a major concern for healthcare professionals.

It is estimated that the percentage of the population of Taiwan aged 65 and older will increase from $9.0 \%$ in 2002 to $13.8 \%$ in 2020 and to $21.7 \%$ in 2035 . $^{7}$ In Taiwan, as in other countries with an growing aging population, hip fracture represents a major and growing healthcare problem. Hip fractures in 1997 resulted in approximately 15,000 hospital admissions. The incidence rate in 1993 for hip fractures in older people in Taiwan was 211 per 100,000 , which is 10 times the incidence rate for the general population aged 15 to $64 .^{8}$ One year after hip fracture, the mortality rate remains high (15.4-16.3\%), and many patients $(26-76 \%)^{9}$ never recover completely in terms of activity of daily living (ADL) functions. ${ }^{8,9}$ All dimensions of health-related quality of life (HRQOL) of these patients are greatly impeded. ${ }^{10}$

Previous studies have reported that elderly patients with hip fracture can benefit from postoperative rehabilitation, rehabilitation on an orthogeriatric unit, early discharge planning programs, or transitional care 
programs. ${ }^{11-18}$ Meta-analyses of controlled trials have also indicated that geriatric assessment improves survival and function in older persons. ${ }^{19,20}$ The majority of these studies analyzed data from Western developed countries, but little is understood about the effects of intervention programs for elderly patients with hip fracture in Asian countries. Taiwan differs substantially from Western developed countries in its healthcare system, clinical practice, case mix, culture, and social organization. For example, anthropometric measures (e.g., body mass index, height, weight, hip axis, and femoral neck length) differ between ethnic groups. ${ }^{21-23}$ Unlike elderly patients in Western countries, the majority of older people in Taiwan continue to reside with their adult married children. ${ }^{24}$ Taiwan's healthcare system also differs from those in most Western countries because of Taiwan's national health insurance, the ability of its citizens to choose and visit clinics in medical centers without a referral, and the underdevelopment of community-based, long-term-care services. $^{25}$

These differences might make the need for and effect of intervention programs for older people with hip fracture different from those of their counterparts in Western countries. Thus, findings from studies conducted in Western countries need to be validated in Taiwan. Therefore, the purposes of this randomized, pilot clinical trial were to develop an interdisciplinary intervention program for hipfractured older people in Taiwan and examine the effectiveness of this intervention program at 1 and 3 months after hospital discharge. It was hypothesized that participants in the interdisciplinary intervention program would use significantly fewer services and have significantly better clinical outcomes, better self-care ability, better quality of life, and fewer depressive symptoms than those who did not.

\section{METHODS}

A single-blinded, randomized experimental design was used to evaluate the effectiveness of the intervention program. Outcomes were followed and compared for participants in the control and experimental groups at 1 and 3 months after discharge.

\section{Participants}

Several inclusion criteria were adopted to minimize the influence of extraneous variables. To be included, participants had to be aged 60 or older, be admitted to the hospital for an accidental single-side hip fracture, be receiving hip arthroplasty or internal fixation, be able to perform full range of motion (ROM) against gravity and against some or full resistance, have a prefracture Chinese Barthel Index (CBI) score greater than 70, and live in northern Taiwan. Patients were excluded if they were severely cognitively impaired and completely unable to follow orders (determined by a score $<10$ on the Chinese Mini-Mental State Examination $(\mathrm{MMSE}))^{26,27}$ or terminally ill.

The sample recruitment process is presented in Figure 1. From September 2001 to November 2003, 1,182 elderly patients diagnosed with fracture were screened. Of these older people, 732 were hospitalized for hip fracture and received surgery. Of these 732 patients, 298 (40.7\%) met the study criteria. For the remaining 434 patients, 299 $(68.9 \%)$ did not meet the functional criteria because of poor

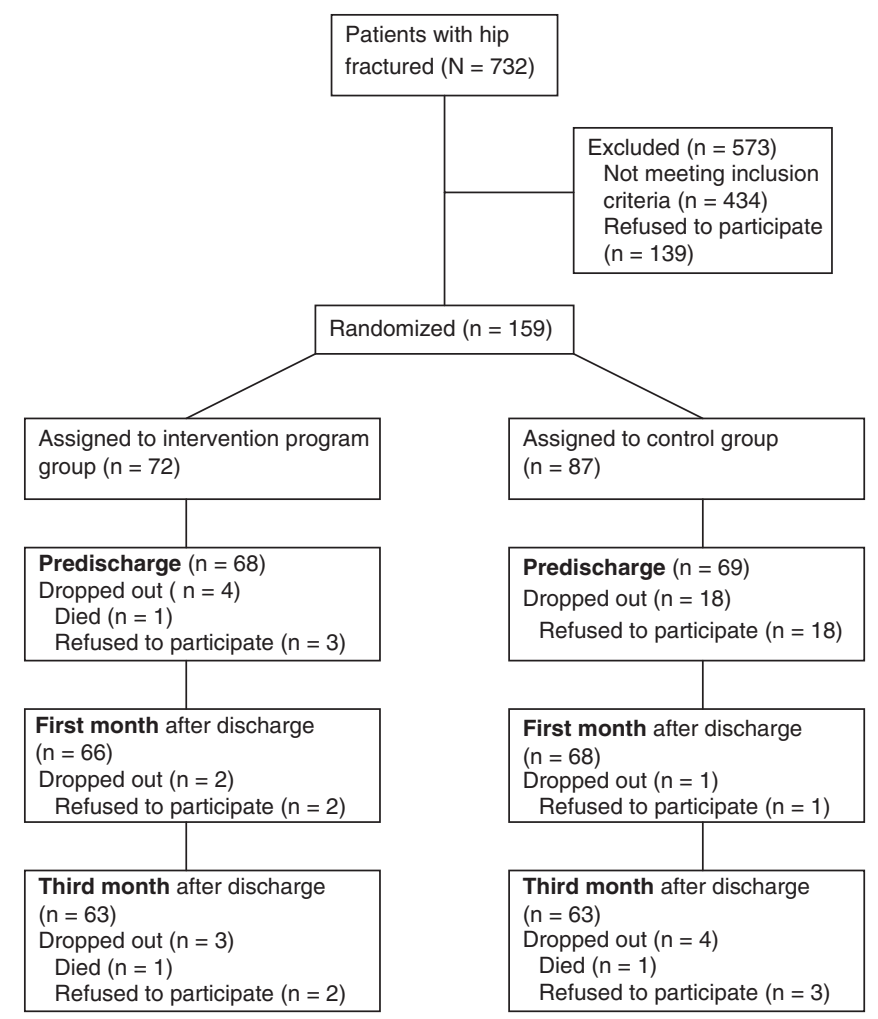

Figure 1. Study flow diagram.

prefracture self-care ability and muscle power or had severe cognitive impairment. In addition, $90(20.7 \%)$ were not contacted at admission, and $45(10.3 \%)$ did not live in northern Taiwan. Of the 159 patients who agreed to participate and were randomly assigned to the experimental or control groups, 137 remained in the study until hospital discharge. Nearly half $(n=139)$ of the eligible patients refused to participate. No significant differences in age $(P=.32)$ or sex $(P=.52)$ were found between patients who declined to participate and those who participated. As shown in Figures 1; 22 subjects dropped out before discharge, one died (experimental group), and 21 others refused further participation. To explore the effect of these losses, the profiles of subjects who remained during the entire study period $(n=126)$ and those who dropped out after having agreed to participate and being randomized $(\mathrm{n}=32)$ were compared. No significant differences were found in age, sex, type of surgery, prefracture or postoperation functional ability, or cognitive functioning, suggesting minimal influence of case loss on study outcomes.

\section{Routine Care (Control Group)}

Routine care of hip-fractured older people in Taiwan currently lacks well-organized, interdisciplinary care protocols and continuity of care. After a fall, patients are generally sent directly to the hospital emergency department (ED), although some patients visit outpatient clinics and enter the hospital via the clinic. Consultations for internal medicine care or anesthesiologists are occasionally made, depending upon the patient's condition. Before surgery, routine examinations include $\mathrm{x}$-ray, electrocardiogram, blood chemistry tests, and blood cell counts. At this time, skin traction is also 
usually performed. Patients then receive internal fixation or arthroplasty.

After surgery, patients usually stay in recovery to monitor their vital signs. After their vital signs have stabilized, patients are then transferred to the trauma or orthopedic ward. During the first 2 to 3 days, nurses usually teach patients how to exercise while still in bed, using caution while changing their position. Pain relief medications are also administered for 2 to 7 days and antibiotics for 2 or 3 days. Hemobags are removed on the third day, and physical therapy usually starts that same day. Physical therapists train patients in using a walker and getting in and out of bed.

The number of physical therapy sessions received by participants while in the hospital varied during the study because of changes in insurance policy. Eighteen subjects in the control group $(28 \%)$ received three physical therapy sessions during hospitalization, whereas the rest $(72 \%)$ received one. Patients are usually discharged from the hospital approximately 7 days after surgery. After hospital discharge, no provision is made for at-home rehabilitation or nursing care. No subjects in the control group received at-home physical therapy. Patients are usually requested to come back to the clinic for checkups approximately 1 month, 3 months, 6 months, and 1 year after hospital discharge, but adherence to this follow-up schedule is poor. Telephone follow-up is seldom provided, and home environments are not assessed. The patients and their families are generally ignorant of rehabilitation, and little health education is offered.

\section{Intervention Program (Experimental Group)}

This study's interdisciplinary intervention program had three components: geriatric consultation service, rehabilitation program, and discharge-planning service. A geriatrician and geriatric nurses provided the geriatric assessment/ consultation; a physical therapist, geriatric nurses, and a rehabilitation physician were responsible for the rehabilitation program; and geriatric nurses delivered the discharge planning service. The routine care and interdisciplinary intervention program are compared in Table 1.

\section{Geriatric Consultation}

The geriatric consultation team had two tasks: to provide comprehensive geriatric assessment and medical supervision to detect potential medical and functional problems and to decrease delays before surgery. In addition to the routine care provided on the day of admission, the geriatric nurse contacted patients and completed an initial assess- ment. Information collected included medical and fall history, vital signs, physical examination, physical and cognitive functional assessment, nutritional status, preoperative risk assessment, current medications, and comorbidity. After the initial assessment, the gerontological nurse reported the results of this initial assessment in person to the geriatrician. The geriatrician then reexamined all subjects and conducted geriatric assessments. These geriatric assessments/consultations included suggestions about time of surgery, use of infection and thromboembolic prophylaxis, postoperative nutritional management, urinary tract management, and delirium management/prevention. The primary surgeon, gerontological nurse, and geriatrician then developed a postoperative care plan.

In addition to providing routine postoperative care, the gerontological nurse visited patients on the first day after surgery to assess for signs of delirium, pain, and postoperative complications. If patients had these signs or complications, the geriatrician made necessary visits. All geriatric consultation suggestions were passed on to the primary surgeon. The healthcare team reviewed the postoperative care plan and made any necessary changes.

\section{Rehabilitation Program}

The tasks of the rehabilitation program were to provide early postoperative rehabilitation to facilitate mobility and plan for hospital discharge, with rehabilitation in the patient's usual environment. Rehabilitation started the first day after surgery and continued in the setting after discharge from the hospital. A geriatric nurse visited the home to participate in delivering the at-home rehabilitation program. The inpatient and at-home rehabilitation programs contained a hip fracture-oriented intervention and a general intervention program for deteriorated physical fitness. During hospitalization after surgery, participants in the experimental group received, in addition to routine care, one physical therapy session a day from a geriatric nurse (total 4 times, $\sim 30$ minutes each), two assessments by a physical therapist (each 20 minutes), and one visit from a rehabilitation physician (20 minutes). After hospital discharge, participants received four home visits during the first month (once a week for $\sim 30$ minutes) and four home visits during the second and third month ( 1 visit every 2 weeks, $\sim 30$ minutes each) from a geriatric nurse. For at-home rehabilitation, patients also received an assessment $(\sim 30 \mathrm{~min}-$ utes) from a physical therapist within 1 week of discharge, 3 weeks after discharge, and 3 months later. Most subjects in the experimental group $(n=67,98.5 \%)$ received the standard physical therapy program, and one $(1.5 \%)$ received

Table 1. Comparison of Routine Care and the Interdisciplinary Intervention Program

\begin{tabular}{lll}
\hline Component in Intervention Program & Interdisciplinary Intervention Program & \multicolumn{1}{c}{ Routine Care } \\
\hline Systemic interdisciplinary involvement & Yes & No \\
Geriatric assessment & Yes & Occasional internal medicine consultation \\
Early rehabilitation & First day postsurgery & 2 or 3 days postsurgery \\
In-home rehabilitation & Yes & No \\
Discharge planning services & Yes & Seldom \\
\hline
\end{tabular}


only physical therapy provided by geriatric nurses but no physical assessment from the physical therapist during hospitalization.

\section{Discharge Planning}

After elderly patients with hip fracture were admitted to the hospital, the gerontological nurse conducted a discharge assessment, including caregiver's competence, resources, family function, patient's self-care ability, and patient and family caregiver's needs for community or long-term care services and made the necessary referrals. The gerontological nurse made a home visit before the patient's discharge to assess the home environment and to suggest any environmental modifications. This nurse coordinated and monitored the patient's use of follow-up services provided, thus ensuring continuity and appropriateness of referrals. $\mathrm{Pa}-$ tients were reminded of follow-up visits to the clinic. Those who missed their follow-up visits to the clinic were contacted by telephone.

The experimental group received, in addition to routine hospital care during hospitalization, approximately 580 minutes of care per patient, including direct interventions and indirect care such as staff meetings and administration. The control group received only routine hospital care and no at-home care.

\section{Outcome Variables}

Outcome variables comprised clinical, service-utilization, self-care ability, and quality-of-life outcomes. Clinical outcomes included ratio of hip flexion, pain intensity, pain intensity and peak force of the fractured limb's quadriceps muscle, recovery of walking ability, recurrence of falls, and mortality. Ratio of hip flexion was defined according to ROM. Recurrence of falls and mortality were assessed using patient and family caregiver self-report. Recovery of walking ability was rated during face-to-face interviews using the walking ability item in the CBI and compared with the prefracture walking ability (retrospectively rated using the CBI at admission). The peak force of the fractured limb's quadriceps was measured using MICROFET2, a portable force evaluation and testing device (Hoggan Health Industries, Inc., Draper, UT). The MICROFET2 was calibrated before each use, and its interrater reliability (intraclass correlation coefficient) obtained before data collection was 0.88 . Pain intensity was measured using a 0 to 10 numeric scale, with 0 indicating no pain and 10 indicating "pain as bad as you can imagine." 28

Service utilization variables included length of hospital stay, emergency room visits, hospital readmission rate, and institutionalization. Self-care ability variables consisted of ability to perform ADLs and instrumental activities of daily living (IADLs). These variables were measured using the CBI and Chinese version of the Lawton and Brody IADL dependency scale, which both have established reliability and validity for older people in Taiwan. ${ }^{29}$

Quality-of-life outcome variables included overall health status. Depressive symptoms were also evaluated. Health status was measured as eight dimensions of health (physical functioning, role limitations due to physical health problems, bodily pain, general health, vitality, social functioning, role limitations due to emotional prob- lems, and mental health) using the Medical Outcomes Study 36-item Short Form (SF-36) Taiwan version. ${ }^{30,31}$ Scores for each dimension range from 0 to 100 , with higher scores representing better health outcomes. The reliability and validity of the SF-36 Taiwan version used in this study has been established. ${ }^{32}$ Depressive symptoms were assessed using the Chinese version of the Geriatric Depression Scale (GDS) short form. ${ }^{33}$ Total scores on the GDS short form can range from 0 to 15 ; the higher the score, the more severe the depressive symptoms. ${ }^{33}$ The internal consistency reliability and construct validity of the GDS short form have been established in older Taiwanese people. ${ }^{34}$

\section{Procedure}

Human subject approval was obtained from the study hospital before collecting data. Research assistants who screened the list of ED admissions twice a day to identify potential subjects recruited subjects from the ED. Those who agreed to participate were randomly assigned to an experimental or control group by the flip of a coin. A neutral third party not involved in delivering the intervention or assessing outcomes flipped the coin. Subjects in the experimental group then received routine hospital care plus the intervention program, and subjects in the control group received only routine hospital care. All subjects were then assessed for clinical outcomes, service utilization outcomes, self-care ability, HRQOL, and depressive symptoms 1 and 3 months after discharge. Different nurses (data collectors) from those who delivered the intervention conducted these follow-up assessments in the home. Data collectors measured the ROM of hip joints and peak force of the fractured limb's quadriceps and in face-to-face interviews collected data on self-care ability, service utilization, quality of life, and depressive symptoms.

\section{Statistical Analysis}

Data were entered into Microsoft EXCEL (Microsoft Corp., Redmond, WA) and analyzed using SPSS (SPSS Inc., Chicago, IL). Statistical significance was determined at $P<.05$. All variables of interest were examined on normal assumptions before taking parametric or nonparametric approaches. Two-sample $t$ tests or chi-square tests were used to compare the two groups before intervention. The two-sample $t$ test was employed to determine the significance of differences in outcome variables between the experimental and control groups.

\section{RESULTS}

\section{Baseline Characteristics}

No significant differences were found in baseline characteristics (sex, age, marital status, education, type of surgery, prefracture ADL and walking ability, living with a spouse during the first month after discharge) of the experimental and control groups using two-sample $t$ test or chi-square analysis (Table 2). Of the 137 participants in the final sample, $69.3 \%$ were female, $54.7 \%$ were married, and $51.1 \%$ were illiterate. Their average age \pm standard deviation was $77.6 \pm 7.71$. About two-thirds $(66.4 \%)$ received internal fixation and $33.5 \%$ received arthroplasty, $53.8 \%$ lived with a spouse 1 month after discharge, and $55.4 \%$ lived with a 
Table 2. Demographic Characteristics of Elderly Subjects with Hip Fracture in the Experimental and Control Groups

\begin{tabular}{|c|c|c|c|c|}
\hline Variable & $\begin{array}{c}\text { Total } \\
(n=137)\end{array}$ & $\begin{array}{l}\text { Experimental Group } \\
\qquad(\mathrm{n}=68)\end{array}$ & $\begin{array}{l}\text { Control Group } \\
(n=69)\end{array}$ & $P$-value \\
\hline Sex, n (\%) & & & & .67 \\
\hline Male & $42(30.7)$ & $22(32.4)$ & $20(29)$ & \\
\hline Female & 95 (69.3) & $46(67.6)$ & $49(71)$ & \\
\hline Age, mean \pm SD & $77.6 \pm 7.7$ & $77.6 \pm 8.3$ & $77.7 \pm 7.1$ & .95 \\
\hline Marital status, n (\%) & & & & .57 \\
\hline Single & $1(0.7)$ & $1(1.5)$ & $0(0)$ & \\
\hline Married & $75(54.7)$ & $36(52.9)$ & $39(56.5)$ & \\
\hline Widowed & $61(44.5)$ & $31(45.6)$ & $30(43.5)$ & \\
\hline Educational background, n (\%) & & & & .75 \\
\hline Illiterate & $70(51.1)$ & $35(51.5)$ & $35(50.7)$ & \\
\hline Primary school & $38(27.7)$ & $17(25)$ & $21(30.4)$ & \\
\hline High school & $18(13.1)$ & $9(13.2)$ & $9(13)$ & \\
\hline College or above & $11(8.0)$ & $7(10.3)$ & $4(5.8)$ & \\
\hline Type of surgery, $n(\%)$ & & & & .31 \\
\hline Arthroplasty & $46(33.6)$ & $20(29.4)$ & $26(37.7)$ & \\
\hline Internal fixation & $91(66.4)$ & $48(70.6)$ & $43(62.3)$ & \\
\hline \multicolumn{5}{|l|}{ Living with spouse, n (\%) } \\
\hline First month after discharge & & & & .85 \\
\hline Yes & $70(53.8)$ & $35(53)$ & $35(54.7)$ & \\
\hline No & $60(46.2)$ & $31(47)$ & $29(45.3)$ & \\
\hline Third month after discharge & & & & .52 \\
\hline Yes & $67(55.4)$ & $32(52.5)$ & $35(58.3)$ & \\
\hline No & $54(44.6)$ & $29(47.5)$ & $25(41.7)$ & \\
\hline $\begin{array}{l}\text { Prefracture Chinese Barthel } \\
\text { Index score, mean } \pm \text { SD }\end{array}$ & $95.6 \pm 11.0$ & $94.6 \pm 14.3$ & $96.5 \pm 6.1$ & .30 \\
\hline $\begin{array}{l}\text { Percentage of patients with } \\
\text { independent walking ability, mean } \pm \text { SD }\end{array}$ & $116.0 \pm 85.3$ & $58.0 \pm 86.6$ & $58.0 \pm 84.1$ & .68 \\
\hline
\end{tabular}

$\mathrm{SD}=$ standard deviation.

spouse 3 months after discharge. Twenty-six orthopedic surgeons cared for these patients. No significant differences were found using chi-square analysis between the number of patients per orthopedist in the experimental and control groups. About one-third of the subjects $(31.4 \%)$ were mildly cognitively impaired (scoring 10-20 on the Chinese MMSE before discharge). To help these subjects complete the face-to-face interviews, a slower pace of questioning, more explanation, and help and validation from family members were used.

\section{Outcome Comparison}

The outcomes for the experimental and control groups were compared at 1 and 3 months after discharge by applying $t$ test or chi-square analysis (Table 3 ). In terms of services used, no significant differences were found between the two groups in number of hospital readmissions, ED visits, and institutionalizations. In terms of clinical outcomes, subjects in the experimental group had a better ratio of hip flexion 1 month after discharge and a better peak force of the fractured limb's quadriceps 3 months after discharge. Significantly, more subjects in the experimental group than in the control group recovered their previous walking ability by the first $(55.4 \%$ vs $37.3 \%)$ and third $(78.1 \%$ vs $62.7 \%)$ months after discharge, but no significant difference was found in pain intensity, mortality, or recurrence of falls between the two groups.

In terms of self-care ability, subjects in the experimental group had better ADLs 1 and 3 months after discharge, but differences in IADLs between the experimental and control groups were not significant. For HRQOL, the experimental group had significantly better outcomes than the control group in bodily pain, vitality, mental health, physical function, and role physical 3 months after discharge. The social functioning outcome 3 months after discharge was close to being significant $(P=.05)$. No significant differences were found between the experimental and control groups in any dimension of HRQOL 1 month after discharge. The experimental group had significantly fewer depressive symptoms than the control group 3 months after discharge, but not at 1 month.

\section{DISCUSSION}

This multidisciplinary intervention program for older people in Taiwan with hip fractures significantly improved some clinical outcomes (ratio of hip flexion, peak force of fractured limb's quadriceps, and walking ability), self-care abilities (ADLs), dimensions of HRQOL (bodily pain, vitality, general mental health, physical functioning, role limitations due to physical health problems), and depressive symptoms 3 months after hospital discharge. These results 
Table 3. Outcome Comparisons at the First and Third Months After Discharge

\begin{tabular}{|c|c|c|c|}
\hline Variable & $\begin{array}{c}\text { Experimental Group } \\
1 \text { Month }(n=66) \\
3 \text { Month }(n=63)\end{array}$ & $\begin{array}{l}\text { Control Group } \\
1 \text { Month }(n=68) \\
3 \text { Month }(n=63)\end{array}$ & $P$-value \\
\hline \multicolumn{4}{|l|}{ Service utilization } \\
\hline \multicolumn{4}{|l|}{ Hospital readmission rate, $\mathrm{n}(\%)$} \\
\hline Within 1 month & $3(4.5)$ & $5(7.6)$ & .72 \\
\hline Within 3 months & $5(7.9)$ & $9(14.1)$ & .27 \\
\hline \multicolumn{4}{|l|}{ Emergency room visit, n (\%) } \\
\hline Within 1 month & $3(4.5)$ & $3(4.4)$ & 1.00 \\
\hline Within 3 months & $4(6.3)$ & $8(12.3)$ & .37 \\
\hline \multicolumn{4}{|l|}{ Institutionalization, n (\%) } \\
\hline Within 1 month & $1(1.5)$ & $3(4.7)$ & .36 \\
\hline Within 3 months & $2(3.2)$ & $3(4.7)$ & .68 \\
\hline Length of hospital stay, mean \pm SD* $^{*}$ & $10.07 \pm 3.67$ & $10.23 \pm 6.51$ & .86 \\
\hline \multicolumn{4}{|l|}{ Clinical outcome } \\
\hline \multicolumn{4}{|l|}{ Ratio of hip flexion, mean \pm SD } \\
\hline At first month & $0.91 \pm 0.38$ & $0.74 \pm 0.34$ & .02 \\
\hline At third month & $0.98 \pm 0.37$ & $1.02 \pm 1.26$ & .84 \\
\hline \multicolumn{4}{|l|}{$\begin{array}{l}\text { Peak force of quadriceps of } \\
\text { fractured limb, mean } \pm S D\end{array}$} \\
\hline At first month & $7.61 \pm 4.54$ & $6.60 \pm 5.10$ & .30 \\
\hline At third month & $10.38 \pm 6.08$ & $7.99 \pm 5.26$ & .04 \\
\hline \multicolumn{4}{|l|}{ Pain intensity, mean $\pm S D$} \\
\hline At first month & $2.10 \pm 2.34$ & $2.72 \pm 2.30$ & .16 \\
\hline At third month & $1.70 \pm 2.24$ & $2.48 \pm 2.71$ & .13 \\
\hline \multicolumn{4}{|l|}{ Recovery of walking ability, $\mathrm{n}(\%)$} \\
\hline At first month & $36(55.4)$ & $25(37.3)$ & .004 \\
\hline At third month & $50(78.1)$ & $32(50.8)$ & .001 \\
\hline \multicolumn{4}{|l|}{ Mortality, n (\%) } \\
\hline Within 1 month & $0(0)$ & $0(0)$ & - \\
\hline Within 3 months & $0(0)$ & $1(1.6)$ & 1.00 \\
\hline \multicolumn{4}{|l|}{ Recurrence of fall, $\mathrm{n}(\%)$} \\
\hline Within 1 month & $7(10.6)$ & $6(9.4)$ & .82 \\
\hline Within 3 months & $12(18.8)$ & $15(24.2)$ & 46 \\
\hline \multicolumn{4}{|l|}{ Self-care ability, mean \pm SD } \\
\hline \multicolumn{4}{|l|}{ Activities of daily living } \\
\hline At first month & $81.43 \pm 14.4$ & $73.8 \pm 19.28$ & .01 \\
\hline At third month & $89.76 \pm 12.89$ & $79.28 \pm 21.28$ & .001 \\
\hline \multicolumn{4}{|l|}{ Instrumental activities of daily living } \\
\hline At first month & $2.81 \pm 1.41$ & $2.28 \pm 1.82$ & .06 \\
\hline At third month & $3.75 \pm 2.03$ & $3.09 \pm 2.48$ & .12 \\
\hline \multicolumn{4}{|l|}{ Quality of life, mean $\pm S D$} \\
\hline \multicolumn{4}{|l|}{ Bodily pain } \\
\hline At first month & $66.74 \pm 26.88$ & $64.04 \pm 25.27$ & .58 \\
\hline At third month & $75.34 \pm 22.9$ & $64.06 \pm 29.89$ & .03 \\
\hline \multicolumn{4}{|l|}{ General health perceptions } \\
\hline At first month & $52.25 \pm 21.37$ & $55.62 \pm 23.39$ & .42 \\
\hline At third month & $57.12 \pm 21.78$ & $49.31 \pm 27.38$ & .11 \\
\hline \multicolumn{4}{|l|}{ Vitality (energy/fatigue) } \\
\hline At first month & $61.43 \pm 23.2$ & $55.00 \pm 25.37$ & 16 \\
\hline At third month & $67.50 \pm 17.36$ & $53.85 \pm 19.54$ & $<.001$ \\
\hline \multicolumn{4}{|l|}{ Social functioning } \\
\hline At first month & $57.00 \pm 27.04$ & $55.25 \pm 29.46$ & .74 \\
\hline At third month & $72.46 \pm 22.51$ & $63.54 \pm 25.89$ & .05 \\
\hline \multicolumn{4}{|c|}{ Role limitations due to emotional problems } \\
\hline At first month & $67.67 \pm 41.74$ & $66 \pm 43.37$ & .83 \\
\hline At third month & $82.29 \pm 35.61$ & $80.55 \pm 34.94$ & .80 \\
\hline
\end{tabular}


Table 3. (Contd.)

\begin{tabular}{|c|c|c|c|}
\hline Variable & $\begin{array}{c}\text { Experimental Group } \\
1 \text { Month }(n=66) \\
3 \text { Month }(n=63)\end{array}$ & $\begin{array}{c}\text { Control Group } \\
1 \text { Month }(n=68) \\
3 \text { Month }(n=63)\end{array}$ & $P$-value \\
\hline \multicolumn{4}{|c|}{ General mental health } \\
\hline At first month & $65.27 \pm 23.56$ & $56.96 \pm 23.51$ & .06 \\
\hline At third month & $67.75 \pm 19.2$ & $58.58 \pm 22.16$ & .02 \\
\hline \multicolumn{4}{|l|}{ Physical functioning } \\
\hline At first month & $23.33 \pm 20.42$ & $18.8 \pm 21.25$ & .25 \\
\hline At third month & $48.35 \pm 30.42$ & $28.22 \pm 27.16$ & $<.001$ \\
\hline \multicolumn{4}{|c|}{ Role limitations due to physical health problems } \\
\hline At first month & $32.95 \pm 38.27$ & $22.00 \pm 39.97$ & 14 \\
\hline At third month & $50.39 \pm 40.45$ & $28.64 \pm 39.94$ & .006 \\
\hline \multicolumn{4}{|c|}{ Geriatric Depression Scale score, mean \pm SD } \\
\hline At first month & $4.37 \pm 3.28$ & $5.20 \pm 4.12$ & 23 \\
\hline At third month & $3.57 \pm 2.99$ & $5.42 \pm 4.21$ & .008 \\
\hline
\end{tabular}

* Using case numbers at discharge, experimental group $(n=68)$, control group $(n=69)$.

$\mathrm{SD}=$ standard deviation.

are consistent with those of previous studies in that moreintensive, home-based rehabilitation programs or multidisciplinary programs effectively improve the self-care and walking abilities of hip-fractured older people. ${ }^{11,13,15,16,35-38}$

This intervention program was also effective in improving the depressive symptoms of hip-fractured older people 3 months after discharge. Although this intervention program did not directly target improving hip-fractured older peoples' quality of life or depressive symptoms, its effects on improving self-care ability and aspects of HRQOL may have indirectly improved quality of life and depressive symptoms. Although no reports were found on the effect of intervention programs on HRQOL in hipfractured older people, it has been reported that self-care ability influences HRQOL and depressive symptoms in this population. ${ }^{10,39,40}$

Nevertheless, the hypothesis that participants in the interdisciplinary intervention program would use significantly fewer services was not supported. As in a previous study, ${ }^{41}$ no significant effect was found on readmission rate, perhaps because of the small number of rehospitalized patients in the current study. The lack of significant effects on fall recurrence, mortality, and institutionalization rate might also have been due to the small number of rehospitalized patients. Similarly, no significant difference was found in the length of the hospital stay for the experimental $($ mean $=10.7)$ and control $($ mean $=10.2)$ groups, unlike a previous study that found that intensive geriatric rehabilitation shortened the mean hospital stay from 42 days to 34 days. ${ }^{13}$ The results of the current study might be due to the already short hospital stays of these subjects, making any further decrease difficult.

One limitation of this study was its single-blind design. Patients and their families were blind to subjects' group assignment, but the personnel delivering the intervention and assessing outcomes were not. However, these personnel were purposely assigned different research duties to minimize the potential influence of bias. Other factors that might have diminished the effect of the single-blind study design on the validity of the results are that self-reported outcome variables (HRQOL) and observed/measured variables (self-care ability, clinical outcomes) supported the effectiveness of the intervention.

Another limitation of this study was the lack of baseline measures for HRQOL before implementing the intervention program. However, the lack of significant differences in demographic characteristics and prefracture self-care ability of the experimental and control groups support the assumption of equivalent preintervention qualities of life and qualities of care for the two groups. A third limitation of this study was that too many variables were investigated. The rationale for including a large number of outcome variables was to gain a more comprehensive view of the intervention's effects and to enhance the likelihood of positive results.

The criteria for selecting subjects excluded older people with severe cognitive impairment and weak muscle power. Thus, the sample may have had better function than the general population of older people in Taiwan with hip fracture. The effect of this intervention program can therefore only be generalized for hip-fractured older people without severe cognitive impairment and with adequate muscle power in their extremities.

In summary, these results suggest that this interdisciplinary intervention program may benefit hip-fractured older people in Taiwan by improving clinical outcomes and self-care abilities 1 and 3 months after discharge and by improving HRQOL and depressive symptoms 3 months after discharge. These results expand current knowledge by providing empiric evidence on the effects of an intervention that includes geriatric assessment, continuous rehabilitation from the first day after surgery to the home setting, and discharge planning on a sample of hip-fractured older Chinese people.

The cost-effectiveness of this interdisciplinary program will be reported in detail in a separate paper. It is estimated that this intervention program would cost proximately $\$ 120$ more than routine care. ${ }^{42}$ The findings of this study suggest that, for a limited increase in cost, physical-related functioning, HRQOL, and mental health for hip-fractured older people in Taiwan may be improved by adding 
geriatric assessment, extending current postsurgical rehabilitation, and providing discharge planning in addition to routine care. Additional long-term effects of this intervention program (e.g., 6 months and 1 year after discharge) will be explored and reported in a future study. This study's results may provide a reference for healthcare providers in countries using similar programs with Chinese/Taiwanese immigrants.

\section{ACKNOWLEDGMENT}

We thank the National Health Research Institute, Taiwan, and Chang Gung Memorial Hospital, Taiwan, for their financial support.

\section{REFERENCES}

1. Mellinger E. Identifying risk factors for and preventing hip fractures in elderly patients. AORN J 1997;66:688-693.

2. Ahmad LA, Eckhoff DG, Kramer AM. Outcome studies of hip fractures. Orthop Rev 1994;23:19-24.

3. Aharonoff GB, Koval KJ, Skovron ML et al. Hip fractures in the elderly: Predictors of one year mortality. J Orthop Trauma 1997;11:162-165.

4. Katz S, Ford AB, Heilpe KG et al. Studies of illness in the aged: Recovery after fracture of the hip. J Gerontol 1964;19:285-293.

5. Magaziner J, Simonsick EM, Kashner TM et al. Predictors of functional recovery one year following hospital discharge for hip fracture: A prospective study. J Gerontol 1990;45:101-107.

6. Norton R, Butler M, Robinson E et al. Declines in physical functioning attributable to hip fracture among older people: A follow-up study of casecontrol participants. Disabil Rehabil 2000;22:345-351.

7. [Projections of the Population of Taiwan Area, Republic of China 1995 to 2036.] Taipei, Taiwan: Manpower Planning Department, Council for Economic Planning and Development, Executive Yuan (Republic of China), 1996 (in Chinese).

8. Tsai YJ, Lin HS, Chow LPA. [Pilot Study on Health Sector Priority Review in Taiwan: By Retrospective Study on the Elderly Hip Fracture]. Taichung, Taiwan: Taiwan Provincial Institute of Family Planning, 1995 (in Chinese).

9. Shyu YI, Chen MC, Liang J et al. Predictors of functional recovery for hip fractured elders at twelve months following hospital discharge: A prospective study on a Taiwanese sample. Osteoporos Int 2004;15:475-482.

10. Shyu YIL, Chen MC, Liang J et al. Changes of quality of life among elderly patients with hip fracture in Taiwan. Osteoporos Int 2004;15:95-102.

11. Adunsky A, Lusky A, Arad M et al. A comparative study of rehabilitation outcomes of elderly hip fracture patients: The advantage of a comprehensive orthogeriatric approach. J Gerontol A Biol Sci Med Sci 2003;58A:M542M547.

12. Huusko TM, Karppi P, Avikainen V et al. Randomised, clinically controlled trial of intensive geriatric rehabilitation in patients with hip fracture: Subgroup analysis of patients with dementia. BMJ 2000;321:1107-1111.

13. Huusko TM, Karppi P, Avikainen V et al. Intensive geriatric rehabilitation of hip fracture patients: A randomized, controlled trial. Acta Orthop Scand 2002;73:425-431.

14. Farnworth MG, Kenny P, Shiell A. The costs and effects of early discharge in the management of fractured hip. Age Ageing 1994;23:190-194.

15. Munin MC, Rudy TE, Glynn NW et al. Early inpatient rehabilitation after elective hip and knee arthroplasty. JAMA 1998;279:847-852.

16. Tinetti ME, Baker DI, Gottschalk M et al. Systematic home-based physical and functional therapy for older persons after hip fracture. Arch Phys Med Rehabil 1997; 78:1237-1247.

17. Von Sternberg T, Hepburn K, Cibuzar P et al. Post-hospital sub-acute care: An example of a managed care model. J Am Geriatr Soc 1997;45:87-91.

18. Crotty M, Whitehead $\mathrm{CH}$, Gray S et al. Early discharge and home rehabilitation after hip fracture achieves functional improvements: A randomized controlled trial. Clin Rehabil 2002;16:406-413.

19. Stuck AE, Siu AL, Wieland GD et al. Comprehensive geriatric assessment: A meta-analysis of controlled trials. Lancet 1993;342:1032-1036.
20. Rubenstein LZ, Stuck AE, Siu AL et al. Impacts of geriatric evaluation and management programs on defined outcomes: Overview of the evidence. J Am Geriatr Soc 1991;39: 8S-16S; discussion 17S-18S.

21. Launer LJ, Harris T. Weight, height and body mass index distributions in geographically and ethnically diverse samples of older persons. Ad Hoc Committee on the Statistics of Anthropometry and Aging. Age Ageing 1996;25:300-306.

22. Wang MC, Aguirre M, Bhudhikanok GS et al. Bone mass and hip axis length in healthy Asian, black, Hispanic, and white American youths. J Bone Miner Res 1997;12:1922-1935.

23. Wang J, Thornton JC, Russell M et al. Asians have lower body mass index (BMI) but higher percent body fat than do whites: Comparisons of anthropometric measurements. Am J Clin Nutr 1994;60:23-28.

24. Lee YJ, Parish WL, Wills R. Sons, daughters, and intergenerational support in Taiwan. Am J Sociol 1994;99:1010-1041.

25. Chen HT. Strategies for developing community-based long term care: From access to health service perspective. In: Lee SD, Wu SC, Chen HT et al, eds. Strategies for Developing Community-Based Long Term Care. Taipei, Taiwan: National Health Research Institutes, 2003, pp 81-95. (In Chinese).

26. Yip PK, Shyu YI, Liu SI et al. The multidisciplinary project of dementia study in northern Taiwan (DSNT) background and methodology. Acta Neurol Taiwan 1997;6:210-216.

27. Yip PK, Shyu YI, Liu SI et al. An epidemiological survey of dementia among elderly in an urban district of Taipei. Acta Neurol Taiwan 1997;1: 347-354.

28. Cleeland CS. Assessment of pain in cancer: Measurement issues. In: Foley KM, ed. Advances in Pain Research and Therapy. New York: Raven Press, 1990, pp 47-55.

29. Chen YJ, Dai YT, Yang CT et al. A Review and Proposal on Patient Classification in Long-Term Care System. Taipei, Taiwan: Department of Health, Republic of China, 1995 (in Chinese).

30. Lu JR, Tseng HM, Tsai YJ. Assessment of health-related quality of life in Taiwan (I). Development and psychometric testing of SF-36 Taiwan version. Taiwan J Public Health 2003;22:501-511 (in Chinese).

31. Tseng HM, Lu JR, Tsai YJ. Assessment of health-related quality of life (II): Norming and validation of SF-36 Taiwan version. Taiwan J Public Health 2003;22:512-518 (in Chinese).

32. Shyu YIL, Lu JF, Liang J. Evaluation of Medical Outcomes Study Short Form36 Taiwan version in assessing elderly patients with hip fracture. Osteoporos Int 2004;15:575-582.

33. Burke WJ, Roccaforte WH, Wengel SP. The short form of the Geriatric Depression Scale: A comparison with the 30-item form. J Geriatr Psychiatry Neurol 1991;4:173-178.

34. Liu CY, Lu CH, Yu S et al. Correlations between scores on Chinese versions of long and short forms of the Geriatric Depression Scale among elderly Chinese. Psychol Rep 1998;82:211-214.

35. Dai YT, Huang GS, Yang RS et al. Functional recovery after hip fracture: Six months' follow-up of patients in a multidisciplinary rehabilitation program. J Formos Med Assoc 2002;101:846-853.

36. Runciman P, Currie CT, Nicol M et al. Discharge of elderly people from an accident and emergency department: Evaluation of health visitor follow-up. J Adv Nurs 1996;24:711-718.

37. Sherrington C, Lord SR, Herbert RD. A randomised trial of weight-bearing versus non-weight-bearing exercise for improving physical ability in inpatients after hip fracture. Aust J Physiother 2003;49:15-22.

38. Tappen RM, Whitehead D, Folden SL et al. Effect of a video intervention on functional recovery following hip replacement and hip fracture repair. Rehabil Nurs 2003;28:148-153.

39. Mossey JM, Mutran E, Knott K et al. Determinants of recovery 12 months after hip fracture: The importance of psychosocial factors. Am J Public Health 1989;79:279-286.

40. Ostir GV, Goodwin JS, Markides KS et al. Differential effects of premorbid physical and emotional health on recovery from acute events. J Am Geriatr Soc 2002;50:713-718.

41. O'Cathain A. Evaluation of a Hospital at Home scheme for the early discharge of patients with fractured neck of femur. J Public Health Med 1994;16:205210.

42. Lee HC. Cost effectiveness of a multidisciplinary rehabilitation model in hip fractured elderly patients with internal fixation operation [masters thesis]. Taoyuan, Taiwan: Chang Gung University, 2004. 